Artigo Original

\title{
A proteção de áreas naturais no contexto do planejamento territorial municipal: estudos de caso na Zona Costeira do Estado de São Paulo
}

\author{
Protection of natural areas in the context of municipal territorial planning: case studies in the \\ Coastal Zone of the State of São Paulo
}

\author{
Elizete Aparecida Checon de Freitas Lima' \\ Victor Eduardo Lima Ranieri"
}

\section{Resumo}

Os municípios que abrigam unidades de conservação em seu território apresentam um papel decisivo para a proteção dessas áreas. Por meio de instrumentos de ordenamento territorial, como o plano diretor e o zoneamento ambiental, o município pode definir uma ocupação antrópica mais adequada à conservação ambiental no entorno das áreas protegidas, presentes em seu território. O presente trabalho teve como principal objetivo investigar o potencial dos instrumentos de planejamento territorial, principalmente o plano diretor na proteção das áreas naturais, em especial, as unidades de conservação. O projeto foi desenvolvido em municípios integrantes da Zona Costeira do Estado de São Paulo. Os resultados obtidos mostraram que os planos diretores apresentaram situações diversificadas quanto à maneira como abordaram a questão da presença e da proteção da unidade de conservação no território do município. A metade dos planos diretores analisados apresentou características que foram associadas com a proteção das UCs, reafirmando o potencial desse instrumento de planejamento territorial na proteção das áreas naturais existentes no município.

Palavras-chave: Áreas protegidas; Unidades de conservação; Plano diretor; Zoneamento ambiental

\section{Abstract}

The municipalities that have protected areas in their territory have a decisive role in the protection of these areas. Through territorial planning instruments, such as the master plan and the environmental zoning, the municipality can define a human occupation more suited to environmental conservation around protected areas, present in its territory. This study aimed to investigate the potential of territorial planning tools, especially the master plan for the protection of natural areas. The project was developed on municipalities of the Coastal Zone of São Paulo State. The results showed that the master plans presented different situations on the way addressed the question of the presence and protection of the protected area in the municipality. Half of the analyzed master plans presented characteristics that were associated with the protection of such areas, reaffirming the potential of territorial planning instrument in the protection of existing natural areas in the municipality.

Keywords: Protected areas; Master plan; Environmental zoning

Doutorado em Ecologia e Recursos Naturais, Professora aposentada da Universidade Estadual Paulista Júlio de Mesquita Filho, Faculdade de Engenharia de Ilha Solteira, email elizete.lima@unesp.br.

' Doutorado em Engenharia Hidráulica e Saneamento, Professor associado da Universidade de São Paulo, Escola de Engenharia de São Carlos, email vranieri@sc.usp.br 


\section{Introdução}

O planejamento territorial cumpre um papel importante na garantia da integridade das áreas protegidas, quando orienta uma ocupação antrópica menos impactante à biodiversidade, no entorno dessas áreas. Para cumprir esse papel, entretanto, os planos espaciais precisam ser construídos numa perspectiva de atenção à proteção das áreas naturais, o que nem sempre é concretizado (FIDELIS \& SUMARES, 2008).

A inclusão do aspecto "proteção de áreas naturais" no planejamento territorial tem sido uma realidade em muitos países. Nos países membros da Comunidade Europeia, por exemplo, deve ser seguida a orientação da Diretiva de Habitats (1992), no sentido de que sejam avaliados os impactos negativos significativos, advindos de planos e projetos, sobre as áreas naturais protegidas integrantes da Rede Natura 2000 (rede de áreas naturais de elevado valor para a conservação da biodiversidade, definidas no território europeu) (PETERSON et al., 2010). A legislação brasileira ainda não prevê a realização da avaliação de impactos decorrentes da execução de planos setoriais ou espaciais de âmbito estratégico sobre as áreas protegidas. É regulamentada a avaliação, apenas, dos projetos passíveis de causar impactos ambientais significativos, incluindo aqueles que possam afetar uma unidade de conservação(UC) ou sua II zona de amortecimento (BRASIL, 2010) no âmbito do licenciamento ambiental de tais projetos (como obras de infraestrutura, por exemplo).

A integração entre o planejamento das áreas protegidas e o planejamento territorial pode ocorrer de diferentes modos. Em alguns casos, os planos de manejo das áreas protegidas tratam apenas de seu planejamento interno, isto é, dentro do limite geográfico definido para a área protegida (FIDELIS \& SUMARES, 2008; GARCIA \& REVAH, 2013). Nesses casos, outros instrumentos de planejamento territorial ficam com a responsabilidade de ordenar o uso do solo no entorno das áreas protegidas. No Brasil, o planejamento do uso do solo no interior das áreas protegidas regulamentadas pela Lei Federal n 9.985 de 2000 (conhecida como Lei do Sistema Nacional de Unidades de Conservação - SNUC) é de competência do órgão responsável pela gestão dessas áreas (denominadas Unidades de Conservação - UC) e o plano diretor municipal é responsável pelo planejamento do entorno da UC. Entretanto, conforme definido pela Lei do SNUC, esse planejamento deve ser realizado em consonância com as normas de utilização da Zona de Amortecimento (ZA) da UC, definidas em seu plano de manejo (BRASIL, 2000). Como afirma Neves (2012), as diretrizes de manejo e as regras estabelecidas para a ZA no plano de manejo da UC precisam ser incorporadas ao plano diretor e em outras normas legais municipais para que elas sejam efetivas. Além disso, o município pode, também delimitar zonas de uso especial ao redor das UCs (VITALLI et, 2009) com o objetivo de

\footnotetext{
I As unidades de conservação correspondem a espaços territoriais legalmente criados pelo poder público e englobam várias categorias com objetivos distintos, de acordo com a Lei Federal 9985/2000 (BRASIL, 2000).

"A zona de amortecimento corresponde a uma área delimitada no entorno da unidade de conservação em que as atividades humanas encontram-se sujeitas a normas e restrições específicas, com o propósito de minimizar os impactos negativos sobre a unidade (BRASIL, 2000).
}

minimizar a pressão antrópica sobre essas áreas protegidas. Nesse sentido, pode-se dizer que as UCs reivindicam um tratamento especial no planejamento territorial municipal, com normas singulares, que as diferenciem do restante do território municipal (GOMES, 2006). Entretanto, a inclusão de UCs em categorias específicas de uso do solo nos planos diretores tem sido realizada, na maioria das vezes, sem o enfrentamento dos conflitos resultantes de sua viabilização (COSTA et al., 2011).

Dentre os vários desafios para a inclusão das UCs no planejamento territorial municipal pode-se citar a dificuldade de articulação entre os governos locais e os órgãos responsáveis pelas UCs. Freitas (2008) investigou vários instrumentos de gestão territorial, incluindo Zoneamento Ecológico e Econômico (ZEE), planos de bacia, planos diretores e planos de manejo de UCs buscando neles, elementos que pudessem favorecer a integração das UCs aos diversos usos do território. Apesar de ter encontrado tais elementos nos instrumentos de gestão analisados, o estudo constatou a falta de articulação entre as instituições, como uma limitação para a utilização adequada dos mesmos.

A existência de um sistema de planejamento territorial integrado, como ocorre em países como Holanda (KOLHOFF \& SLOOTWEG, 2005) e Finlândia (SÖDERMAN \& SAARELA, 2010), poderia favorecer a articulação necessária entre os diversos níveis de governo, considerando desde a escala local até a regional e nacional. Apesar do planejamento territorial no Brasil ainda não estar organizado como um sistema integrado, os planos diretores municipais poderiam ser elaborados, com vistas à integração entre diferentes recortes e escalas de planejamento, considerando as informações e diretrizes provenientes de planos como o ZEE e os planos de bacia, dentre outros (SANTOS, 2014; SANTOS \& RANIERI, 2013).

De modo similar, a Avaliação Ambiental Estratégica (AAE), apontada como um modo eficiente de incluir a conservação da natureza no contexto do planejamento territorial (SÖDERMAN \& SAARELA, 2010), poderia favorecer a construção de planos diretores mais inclusivos em relação às áreas protegidas existentes num município. Aspectos como a coordenação entre os instrumentos de planejamento atuantes no entorno das áreas protegidas (GARCIA \& REVAH, 2013; ESTEVES \& SOUZA, 2014) e, também, uma maior discussão entre os atores envolvidos (FABBRO NETO \& SOUZA, 2009) poderiam ser facilitados com a incorporação da AAE na construção do plano diretor.

Considerando a multiplicidade de condiçõos de existência e de administração dos vários municípios brasileiros supõe-se também uma variedade de situações relativas à proteção das áreas naturais que ocorrem em seus domínios territoriais. Como o município considera a UC existente em seu território? Existe uma preocupação expressa em seu plano diretor com relação à proteção da UC? As leis de uso do solo ou de zoneamento, quando existentes no município,

"IO plano diretor municipal é um instrumento de planejamento do território definido na legislação brasileira pela Lei Federal n 10257, de 2001 (Estatuto da Cidade), que estabeleceu a obrigatoriedade de sua elaboração nos municípios com mais de 20000 habitantes, além daqueles situados em áreas metropolitanas e de interesse turístico, dentre outras especificidades (BRASIL, 2001). 
definem uma zona especial de proteção no entorno da UC? O plano diretor articula-se com o plano de manejo da UC?

Para responder a essas questões, o presente trabalho analisou planos diretores de catorze municípios que abrigam unidades de conservação em seu território, buscando neles identificar como as UCs eram consideradas no planejamento municipal. Com o desenvolvimento dessa pesquisa, espera-se aumentar o entendimento a respeito da proteção das áreas naturais no contexto do planejamento territorial municipal, configurando a interação de dois importantes instrumentos da política ambiental. A área escolhida para estudo foi a Zona Costeira do Estado de São Paulo. As características dessa região incluindo, a existência do bioma Mata Atlântica, de relevância internacional, um grande número de UCs e uma ocupação antrópica significativa e variada, agregam complexidade ao planejamento dos municípios, conferindo à região as características necessárias para a condução da presente pesquisa.

\section{2 Área de estudo}

Com uma área de cerca de $27.000 \mathrm{~km}^{2}$ e uma extensão de 700 km, a Zona Costeira do Estado de São Paulo (ZCESP) abriga a maior parte da Mata Atlântica remanescente do estado, grande parte dela, protegida como unidades de conservação (SÃO PAULO, 2014). A Mata Atlântica é um dos hotspots mundiais, abrigando uma grande diversidade de espécies, muitas delas endêmicas. Considerando-se todos os fragmentos remanescentes maiores que três hectares, apenas $12,5 \%$ do bioma estão conservados. A região foi declarada Reserva da Biosfera pela UNESCO e Patrimônio Nacional, pela Constituição Federal de 1988 (SOS MATA ATLÂNTICA, 2015).

De acordo com o Plano Estadual de Gerenciamento Costeiro (Lei Estadual 10019, de 03 de julho de 1998), a zona costeira compreende, na área terrestre o espaço geográfico delimitado pelo divisor de águas de drenagem atlântica no território paulista. Essa lei dividiu a zona costeira paulista em quatro setores, de acordo com suas características socioambientais: Litoral Norte, Baixada Santista, Complexo Estuarino-Lagunar de Iguape-Cananéia e Vale do Ribeira. Apesar de apresentar os limites físicos de seus municípios distantes da orla marítima, o Vale do Ribeira influencia diretamente os ecossistemas costeiros, considerando sua bacia de drenagem na vertente atlântica (SÃO PAULO, 2014).

\section{Procedimentos metodológicos}

A pesquisa foi conduzida por meio da análise documental, tendo como objeto de estudo os planos diretores de municípios abrangidos pelas unidades de conservação selecionadas.

A primeira etapa consistiu na seleção das unidades de conservação que integrariam o estudo. Foram consideradas apenas as unidades de conservação do grupo de proteção integral e situadas na porção terrestre da Zona Costeira do Estado de São Paulo (ZCESP). Outro critério adotado para a seleção das unidades de conservação foi a existência de plano de manejo aprovado pelo Conselho Estadual de Meio Ambiente (CONSEMA), na ocasião da consulta realizada na página da Fundação Florestal no mês de março de 2015. As

Tabela 1 - UCs selecionadas como objeto de estudo e os municípios por ela abrangidos, divididos pelo setor a que pertencem, de acordo com o Plano Estadual de Gerenciamento Costeiro (Lei Estadual 10019/1998). Estão indicadas as datas de publicação dos planos de manejo consultados. Os documentos referentes ao ZEE de cada setor do litoral paulista encontram-se identificados por meio dos números dos Decretos Estaduais (DE) e suas respectivas datas de aprovação. Os planos diretores estão identificados por meio dos números de suas respectivas leis municipais

\begin{tabular}{|c|c|c|c|}
\hline $\begin{array}{l}\text { Unidades de } \\
\text { Conservação }\end{array}$ & $\begin{array}{c}\text { Litoral Norte } \\
\text { ZEE DE 62913/2017 }\end{array}$ & $\begin{array}{c}\text { Baixada Santista } \\
\text { ZEE DE } 58996 / 2013\end{array}$ & Vale do Ribeira \\
\hline $\begin{array}{l}\text { PESM } \\
\text { Plano de Manejo } 2006\end{array}$ & $\begin{array}{c}\text { Ubatuba - Lei no } \\
711 / 1984 \\
\text { Caraguatatuba - Lei nº } \\
\text { 42/2011 } \\
\text { São Sebastião - Lei nº } \\
\text { 01/2014 }\end{array}$ & 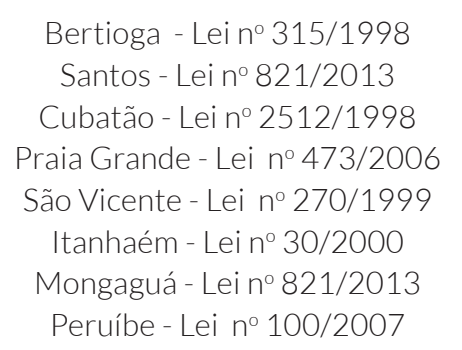 & Juquitiba - Lei n 1507/2007 \\
\hline $\begin{array}{l}\text { PEXJ } \\
\text { Plano de Manejo } 2010\end{array}$ & & $\begin{array}{l}\text { Praia Grande - Lei n 473/2006 } \\
\text { São Vicente - Lei n 270/1999 }\end{array}$ & \\
\hline $\begin{array}{l}\text { PECB } \\
\text { Plano de Manejo } \\
2008\end{array}$ & & & $\begin{array}{c}\text { Sete Barras - Lei nº } \\
\text { 1462/2008 } \\
\text { Tapiraí - Lei nº49/2011 }\end{array}$ \\
\hline $\begin{array}{l}\text { PEl } \\
\text { Plano de Manejo } 2008\end{array}$ & & & $\begin{array}{l}\text { Sete Barras - Lei no } 1462 \\
\text { /2008 }\end{array}$ \\
\hline
\end{tabular}


unidades de conservação selecionadas para estudo foram o Parque Estadual Serra do Mar (PESM), o Parque Estadual Xixová-Japuí (PEXJ), o Parque Estadual Carlos Botelho (PECB) e o Parque Estadual Intervales (PEI).

A seguir foi realizado um levantamento e análise dos planos diretores dos municípios abrangidos por cada uma das unidades de conservação selecionadas. Os municípios da ZCESP que atenderam os requisitos dessa pesquisa e tiveram seus planos diretores analisados foram: Ubatuba, Caraguatatuba, São Sebastião, Bertioga, Cubatão, Santos, Praia Grande, São Vicente, Mongaguá, Itanhaém, Peruíbe, Juquitiba, Sete Barras e Tapiraí (Tabela 1).

Os planos diretores foram analisados por meio da análise de conteúdo (BARDIN, 2016), Inicialmente, realizou-se uma leitura flutuante em toda extensão do documento, com a finalidade de identificarem-se as partes de interesse da investigação, especialmente, aquelas relacionadas ao ordenamento territorial do município e às políticas e diretrizes relativas à proteção das unidades de conservação. Num segundo momento, realizou-se leitura detalhada das partes previamente identificadas nos documentos. Com base nessa análise, foi possível estabelecer categorias de abordagem das UCs nos planos diretores investigados.

\section{Caracterização das UCs e dos municípios por elas abrangidos}

O Parque Estadual Serra do Mar (PESM), criado por meio do Decreto 10251 (30/08/1977) e ampliado em 2010 é a maior área de proteção integral do litoral brasileiro, conectando as florestas da Serra do Mar desde o Rio de Janeiro e Vale do Ribeira, até o Paraná (Figura 1).

Com uma área de 332 mil ha, o PESM engloba 25 municípios paulistas, sendo treze deles localizados na área de estudo (Tabela 2). Os municípios de Ubatuba, Caraguatatuba, São Sebastião encontram-se localizados no Litoral Norte. Esse setor da região costeira tem sua economia caracterizada pela intensa especulação imobiliária e pela sazonalidade decorrente da predominância do turismo veranista (SÃO PAULO, 2017). A urbanização acelerada, não acompanhada do devido ordenamento territorial representa um dos principais desafios à gestão desse parque (SÃO PAULO, 2006).

Os municípios de Bertioga, Santos, Cubatão, Praia Grande, São Vicente, Itanhaém, Mongaguá e Peruíbe, localizam-se na Baixada Santista, o setor mais industrializado e fortemente antropizado da região costeira. Nessa região encontra-se o maior porto do país (Porto de Santos) e o complexo industrial de Cubatão, dentre alguns dos principais empreendimentos econômicos. Acrescenta-se, ainda, o mais recente ciclo de expansão produtiva relacionado às atividades de petróleo e gás na bacia de Santos (SÃO PAULO, 2013).

O município de Santos caracteriza-se como pólo regional, notadamente por sua função portuária, enquanto Cubatão configura-se como um pólo especializado, tanto no aspecto logístico, como da indústria pesada. Praia Grande e São Vicente compartilham funções de suporte logístico e de provimento de ofertas de lazer e de turismo, enquanto Bertioga, Itanhaém, Mongaguá e

Figura 1 - Localização do PESM na ZCESP

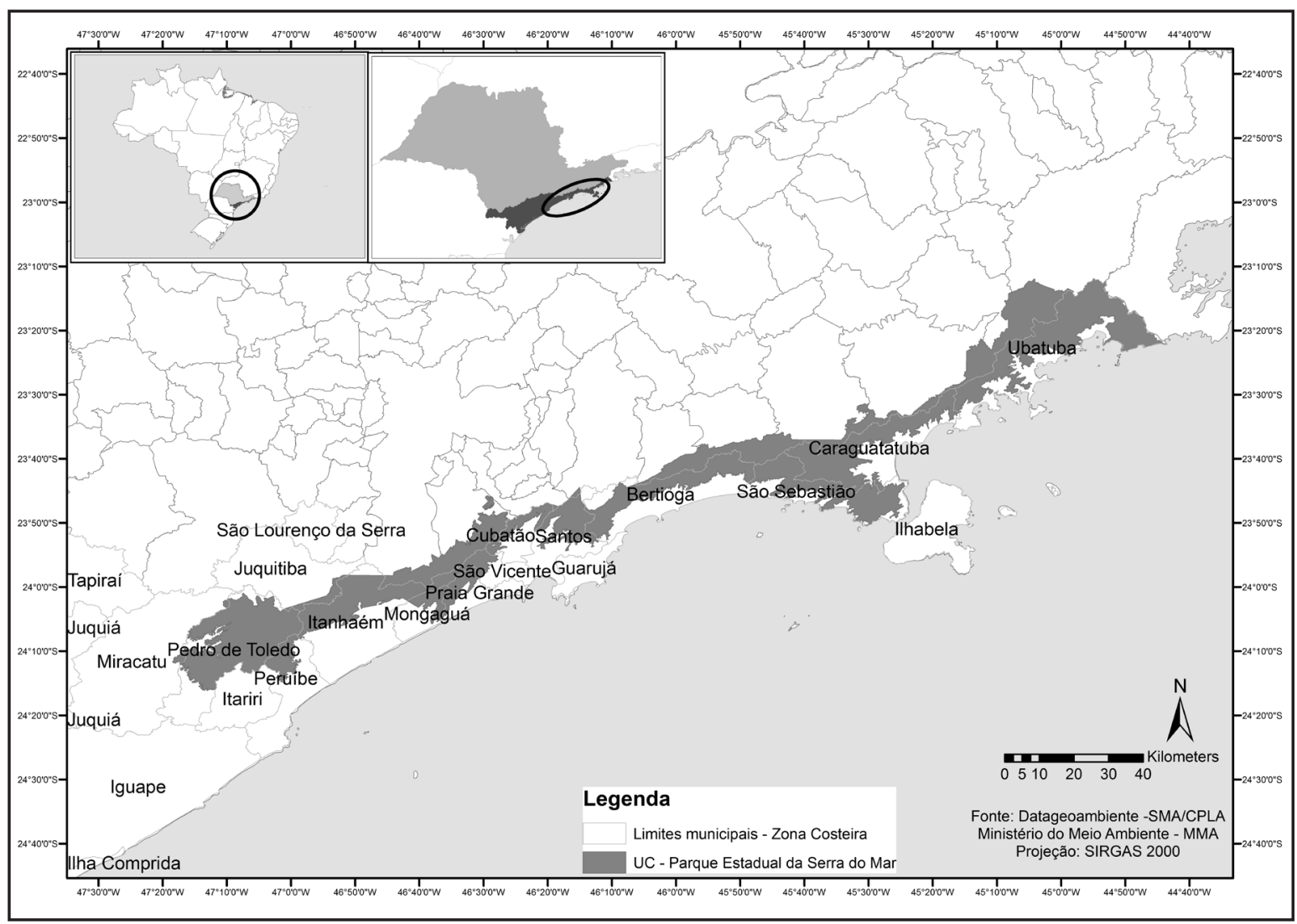


Peruíbe apresentam funções claramente ligadas ao lazer e ao turismo. Apesar de seu desenvolvimento econômico, a região da Baixada Santista apresenta problemas relacionados à carência de infraestrutura de saneamento ambiental, que se agravam nos meses de verão, quando aumenta a demanda por esse serviço, devido ao grande afluxo de turistas (SÃO PAULO, 2013).

No Vale do Ribeira estão localizados os municípios de Juquitiba, com $5 \%$ de seu território, abrangido pelo PESM e Pedro de Toledo (sem plano diretor). O Vale do Ribeira é o setor da ZCESP com menor desenvolvimen- to econômico na região costeira, com predomínio de atividades rurais e extrativas, além de também possuir considerável potencial turístico (SÃO PAULO, 2006). Por ocasião da realização do presente estudo, a região ainda não dispunha de um ZEE.

O Parque Estadual Xixová-Japuí (PEXJ) encontra-se localizado na Baixada Santista, englobando parte dos municípios de Praia Grande e de São Vicente (Figura 2). A criação do parque data de 27 de setembro de 1993, por meio do Decreto Estadual 37536. Apresenta uma área de 901 ha (600 ha de área terrestre e 301 ha de área marinha). A

Tabela 2 - Municípios abrangidos pelo PESM, na área de estudo

\begin{tabular}{lccc}
\hline \multicolumn{1}{c}{ Município } & $\begin{array}{c}\text { \% da área do município } \\
\text { abrangida pelo PESM }\end{array}$ & População & IDHM $^{*}$ \\
\hline Ubatuba & 79,58 & 78801 & 0,751 \\
Caraguatatuba & 78,27 & 100840 & 0,759 \\
São Sebastião & 59,28 & 73942 & 0,772 \\
Bertioga & 49,92 & 47645 & 0,730 \\
Cubatão & 49,93 & 118720 & 0,737 \\
Santos & 46,83 & 419400 & 0,840 \\
São Vicente & 57,69 & 332445 & 0,768 \\
Praia Grande & 31,25 & 262051 & 0,754 \\
Mongaguá & 27,94 & 46293 & 0,754 \\
Itanhaém & 36,31 & 87057 & 0,745 \\
Peruíbe & 20,42 & 59773 & 0,749 \\
Juquitiba & 5,35 & 28737 & 0,709 \\
Pedro de Toledo & 65,94 & 10204 & 0,696 \\
\hline
\end{tabular}

Fonte: SÃO PAULO (2006) e ATLAS BRASIL (2013). *Índice de Desenvolvimento Humano Municipal.

Figura 2- Localização do PEXJ na ZCESP

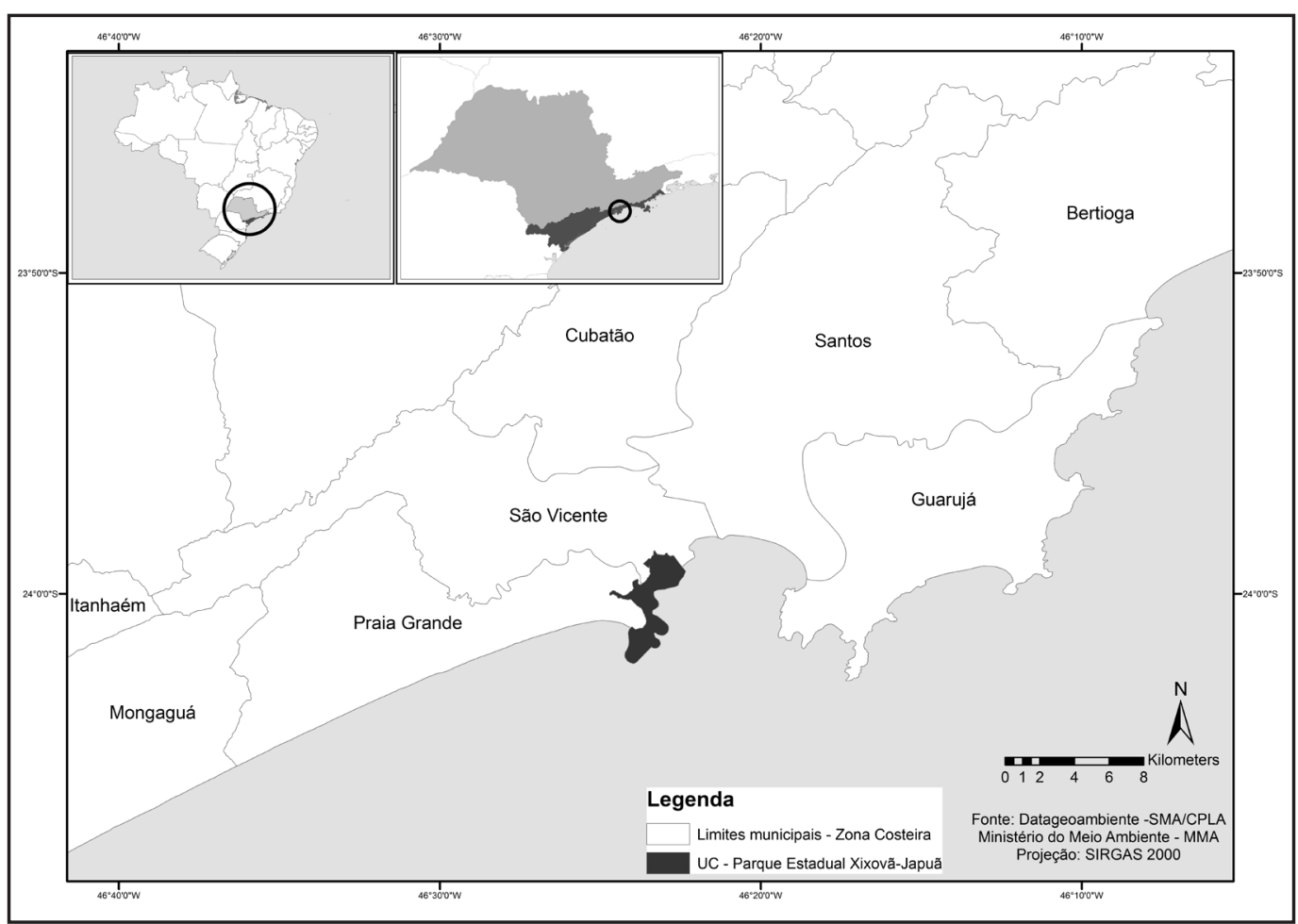


área abrangida pelo parque no Município de Praia Grande corresponde a 554 ha (61,5\% do território), tendo o Bairro Canto do Forte como entorno imediato. No Município de São Vicente, o parque engloba 347 há (38, 5\% do território), nos bairros Japuí e Parque Prainha (SÃO PAULO, 2010).

O Parque Estadual Carlos Botelho (PECB) foi criado por meio do Decreto Estadual 19499, de 10 de setembro de 1982. Apresenta uma área de 37644 ha, abrangendo na área de estudo, território dos municípios de Sete Barras (22417 ha) e Tapiraí (1141 ha), localizados no setor Vale do

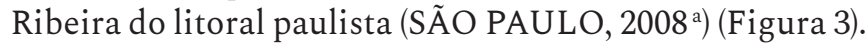

O município de Sete Barras possui uma população de 13000 habitantes e um IDHM de 0,673, classificado como médio. Tapiraí, por sua vez, apresenta um IDHM de 0,681, também classificado como médio e uma população de cerca de 8000 habitantes, segundo o censo do IBGE de 2010 (ATLAS BRASIL, 2013). De acordo com o plano de manejo, os municípios localizados no entorno do parque encontram-se em fase de elaboração e implantação de seus planos diretores, não apresentando, ainda, leis específicas para proteção e controle ambiental. A falta de diretrizes e normas de ordenamento do uso e ocupação do solo é apontada como um dos principais problemas identificados nos municípios de entorno (SÃO PAULO, $2008^{\text {a) }}$.

O Parque Estadual de Intervales (PEI) foi criado em 08 de junho de 1995, por meio do Decreto 40135. O parque está inserido em duas sub-regiões geográficas distintas: a sub-região do Vale do Ribeira (zona costeira) e a subregião do Vale do Alto Paranapanema (Figura 3). O PEI possui uma área total de 41.704 ha. Localizado na área núcleo do Contínuo Ecológico de Paranapiacaba, protege, juntamente com outras unidades de conservação, o segundo e mais importante corredor ecológico de Mata Atlântica do Estado de São Paulo. Na área de estudo, o parque abrange os municípios de Sete Barras (1,44\% do território), Eldorado (9,73\% do território) e Iporanga (16,04\% do território), esses dois últimos, sem plano diretor (SÃO PAULO, 2008 ${ }^{\mathrm{b}}$ ).

\section{Resultados e Discussão}

\subsection{Análise dos planos diretores dos municípios abrangidos pelo PESM}

Dentre os municípios abrangidos pelo PESM integrantes dessa pesquisa, os planos diretores de Cubatão, Santos, Itanhaém e Juquitiba não apresentaram qualquer menção a esse parque. No caso do plano diretor de Santos é apresentada uma divisão do município em área urbana, área de expansão urbana e área de proteção e conservação ambiental. Tais áreas seriam, de acordo com o documento, delimitadas posteriormente por meio de leis específicas. Entretanto, nenhuma delas especifica o PESM ou seu entorno. O plano diretor de Bertioga, por sua vez, menciona o PESM, mas apenas para considerá-lo como uma área de preservação permanente.

Figura 3 - Localização do PECB e do PEI na ZCESP.

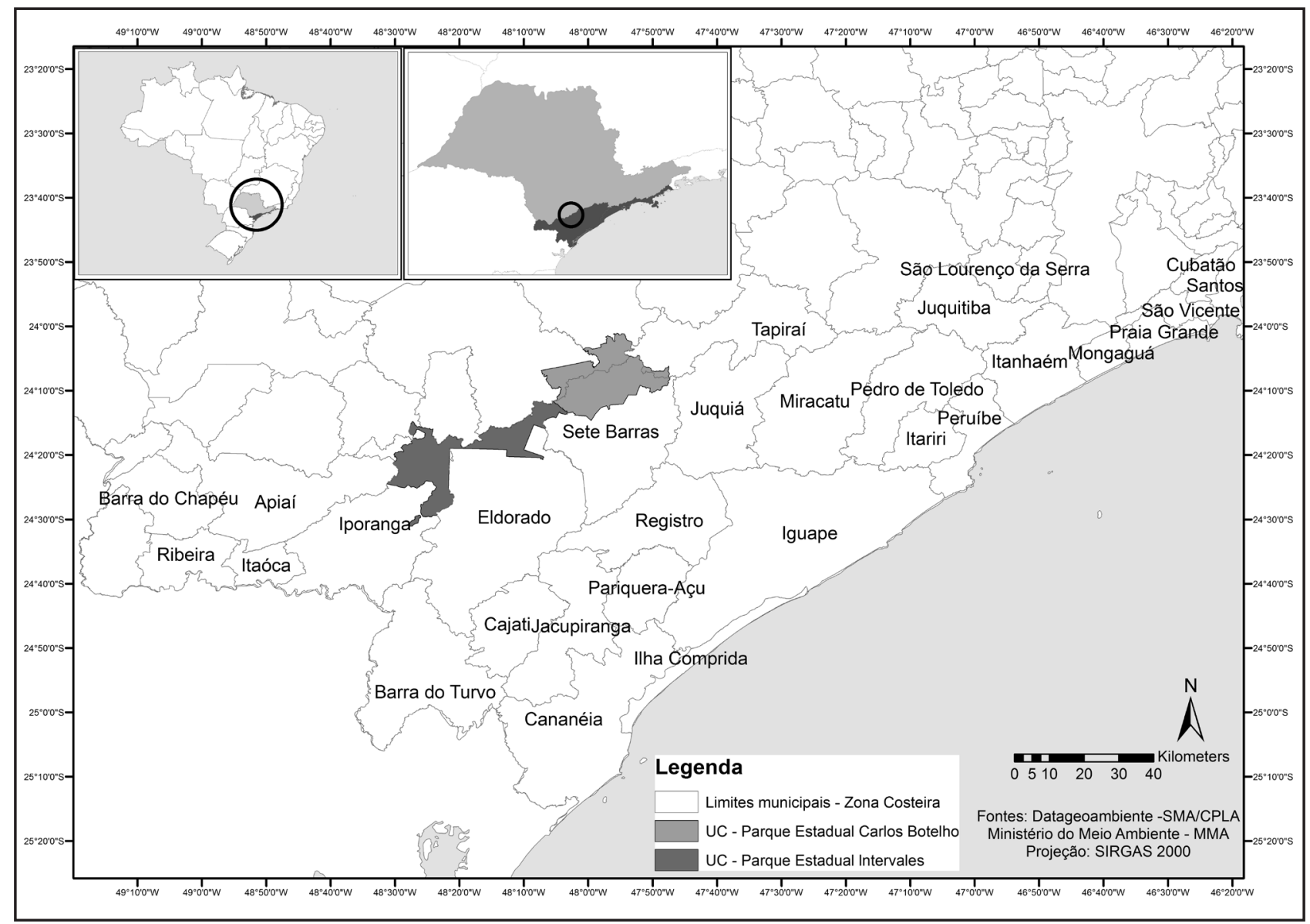


Os demais planos diretores analisados abordaram o PESM, seja por sua inclusão explícita no ordenamento do território, pela designação de uma zona de proteção ao seu redor ou por definirem diretrizes específicas visando sua proteção. Esse foi o caso dos planos diretores dos municípios de Caraguatatuba, Mongaguá, Peruíbe, Praia Grande, São Sebastião, São Vicente e Ubatuba. No caso do plano diretor de Ubatuba, o PESM correspondeu à Z8, denominada Zona do PESM, destinada à preservação ambiental. Entretanto, nenhuma diretriz específica para a proteção do PESM foi verificada nesse plano diretor.

$\mathrm{O}$ plano diretor de Caraguatatuba estabeleceu uma macrozona constituída pelo PESM, denominada de Macrozona de Proteção Ambiental. Além disso, esse plano estabeleceu uma área de proteção no entorno do PESM, como uma faixa lindeira de 100 metros entre o parque e a área urbanizada, incluída na Macrozona de Desenvolvimento Urbano. Também nesse plano diretor, não foi apresentada nenhuma diretriz específica para essa área ou para a proteção do PESM.

O plano diretor de São Sebastião definiu um zoneamento municipal em que o PESM integrava a Macroárea de Proteção Ambiental. O plano indicou, ainda, que a Lei de Uso do Solo deveria delimitar uma zona de proteção no entorno do PESM. Na Política de Unidades de Conservação Ambiental, apresentada no plano diretor, aparece como uma de suas diretrizes, "promover a utilização sustentável da franja envoltória de transição para o limite do PESM com atividades turísticas, como forma de garantir a proteção do Parque."

No plano diretor de São Vicente não foi apresentado o zoneamento municipal. No entanto, a Lei de Uso e Ocupação do Solo do Município de São Vicente - Lei Complementar $n^{\circ} 271$, de 1999 apresentou uma divisão do território municipal, com o PESM incluído na categoria Preservação Permanente para o Desenvolvimento Sustentável, integrando a zona não urbanizável, de acordo com informações obtidas no plano de manejo do PEXJ (SÃO PAULO, 2010). Não foi verificada, entretanto, nenhuma diretriz específica voltada para a proteção do PESM no plano diretor de São Vicente.

O PESM foi incluído na Macrozona de Preservação Permanente, integrante da Macroárea Ambiental, de acordo com o plano diretor de Mongaguá. Nos parâmetros de uso e ocupação do solo para a Macroárea Ambiental foi estabelecido que deveria ser observada a preservação do PESM. Foi definida como uma das diretrizes para a Macrozona de Ocupação Sustentável, integrante da Macroárea de Transição Urbano-Rural, "consolidar a tendência de conversão das áreas rurais em chácaras de recreio, também como estratégia para preservação do PESM e das Reservas Indígenas, incentivando processos de preservação e recomposição do ambiente natural". Além disso, "a valorização da área turística, da orla marítima, das reservas indígenas, da Mata Atlântica, do PESM e da área rural como fatores de atração dos turistas e de ativação econômica da cidade" aparece no plano como uma de suas diretrizes.

O plano diretor de Peruíbe dividiu o território municipal em duas macrozonas: Macrozona de Proteção, constituída por unidades de conservação, dentre as quais o PESM e a Macrozona Rural de Desenvolvimento Agroambiental, que inclui o Setor de Amortecimento do PESM, em correspondência com a zona de amortecimento do PESM. Como objetivo para esse setor o plano cita "a compatibilização entre o uso agrícola e o turismo rural com as necessidades ambientais de uma zona de amortecimento". Observa-se, nesse caso, uma integração entre o plano diretor municipal e o plano de manejo do PESM, instrumento de planejamento da unidade de conservação responsável por delimitar sua zona de amortecimento, além de definir as normas de uso da mesma.

O plano diretor de Praia Grande apresentou uma macrozona correspondente ao PESM e Morro do Estaleiro. Outra macrozona estabelecida no plano, denominada Área de Transição, corresponde a uma área de proteção do PESM, localizada "entre a margem esquerda do Rio Preto e do Rio Branco e os limites do PESM". Essa área teria o objetivo de proteger o PESM da pressão antrópica, além de preservar os remanescentes de restinga e, para tal, "deveria ser destinada a atividades de apoio urbano e ao turismo de baixa intensidade de ocupação, em conformidade com as diretrizes do Zoneamento Ecológico Econômico e do Plano de Manejo do PESM para sua Zona de Amortecimento". O plano diretor apontou, ainda, duas diretrizes específicas para a proteção do PESM. A primeira corresponde à "fiscalização no PESM contra ocupações clandestinas; proposição e implementação de programas de aproveitamento de seu potencial turístico, educativo e científico, em colaboração com o Estado, em particular, com o Instituto Florestal, observadas as diretrizes de seu Plano de Manejo". A segunda diretriz trata da "implantação da base mínima correspondente ao ponto de visitação e fiscalização no 29 do Plano de Manejo do Parque Estadual da Serra do Mar, assim como a demarcação das trilhas ecológicas, a partir desse ponto, em especial da trilha da Cachoeira".

\subsection{Planos diretores dos municípios abrangidos pelo PEXJ}

No plano diretor de São Vicente não foi apresentado o zoneamento municipal. No entanto, a Lei de Uso e Ocupação do Solo do Município de São Vicente - Lei Complementar no 271 , de 1999 apresentou uma divisão do território municipal, com o PEXJ incluído na categoria Preservação Permanente para o Desenvolvimento Sustentável, integrando a zona não urbanizável, de acordo com informações obtidas no plano de manejo do PEXJ (SÃO PAULO, 2010). As áreas imediatamente adjacentes ao PEXJ, inseridas em faixa non aedificandi entre as cotas 5 e $25 \mathrm{~m}$, foram classificadas como Zona Urbana ou Urbanizável Imediata (UP1), para o caso do bairro Japuí, e como Zona Urbana ou Urbanizável de Desenvolvimento Turístico (UP4), para o bairro Parque Prainha, marinas e remanescentes vegetais às margens do Canal do Mar Pequeno. Dentre as diretrizes ambientais apresentadas no plano diretor de São Vicente é citada a regulamentação da fiscalização do PEXJ, por meio da efetivação de Convênio com o Governo do Estado. 
O macrozoneamento do Município de Praia Grande especificou uma macrozona correspondente ao PEXJ, denominada Zona Especial de Interesse Ecológico 2. Ao longo de todo o perímetro do PEXJ foi proposta, também, a criação de uma faixa "non aedificandi" de largura variável, correspondente às áreas compreendidas entre as curvas de nível de cota 5 (cinco) metros e 25 (vinte e cinco) metros.

No plano diretor de Praia Grande foi também citado que o PEXJ "deverá ser objeto de atenção especial por parte do Executivo municipal, tanto na fiscalização contra ocupações clandestinas quanto na proposição e implementação de programas de aproveitamento de seu potencial turístico, educativo e científico, em colaboração com o Estado, em particular, com o Instituto Florestal, observadas as diretrizes de seus respectivos planos de manejo".

\subsection{Planos diretores dos municípios abrangidos pelo $\mathrm{PECB}$}

O plano diretor do Município de Sete Barras não mencionou o PECB em seu zoneamento municipal. No plano diretor constavam apenas, dentre as ações propostas para a consecução dos objetivos do Plano Estratégico de Sustentabilidade, "promover a conservação das áreas de proteção ambiental, como o Parque Estadual Carlos Botelho e o Parque Estadual Intervales. O plano diretor do Município de Tapiraí não fez qualquer menção ao PECB.

\subsection{Planos diretores dos municípios abrangidos pelo $\mathrm{PEI}$}

O plano diretor do Município de Sete Barras não mencionou o PEI em seu zoneamento municipal. No plano diretor constam apenas, dentre as ações propostas para a consecução dos objetivos do Plano Estratégico de Sustentabilidade, "promover a conservação das áreas de proteção ambiental, como o Parque Estadual Carlos Botelho e o Parque Estadual Intervales".

\subsection{A abordagem das UCs nos planos diretores analisados}

A análise dos planos diretores indicou que os mesmos apresentaram situações diversificadas quanto à maneira como abordaram a questão da presença e da proteção das unidades de conservação no território do município. Essas diversas abordagens foram organizadas em quatro categorias: $0,1,2$ e 3 . A categoria 0 indica um nível de abordagem nulo, sem qualquer menção à existência da unidade de conservação objeto de análise no plano diretor. A categoria 1, por outro lado, já indica um nível maior de consideração da unidade de conservação pelo plano diretor. Nessa categoria, foram incluídos aqueles planos diretores que apenas mencionaram a UC como uma área a ser conservada. Na categoria 2 foram incluídos aqueles planos diretores que incluíram a unidade de conservação no zoneamento municipal e (ou) definiram diretrizes específicas para sua proteção. Alguns desses planos diretores, por exemplo, incluíram as UCs em macrozonas específicas, macroáreas ou, ainda, zonas, configurando uma variedade de termos para designar as divisões do território municipal. A última categoria definida (3) incluiu os planos diretores que explicitaram uma articulação com o plano de manejo da UC.

A Tabela 3 apresenta os diversos planos diretores organizados de acordo com essas quatro categorias. Observa-se que dos catorze planos diretores analisados, cinco sequer citaram as UCs investigadas nesse estudo e dois apenas fizeram menção a elas como áreas a serem conservadas sem, contudo, incluí-las no ordenamento territorial ou indicar diretrizes para sua proteção. Por outro lado, foram identificados sete planos diretores com um grau maior de inclusão das UCs (categorias $2 \mathrm{e}$ 3) no ordenamento territorial municipal, confirmando seu potencial enquanto instrumento de proteção dessas áreas naturais, em nível local (Tabela 3).

A construção de um plano diretor em um município que abriga em seu território unidades de conservação deveria, ao menos, "identificar as unidades de conservação integral, mesmo que seja somente para afirmar que não se destinam ao adensamento e à utilização direta pelo homem" (GOMES, 2006). Tal nível de abordagem das UCs no planejamento municipal, identificado nesse estudo como categoria 1 , entretanto, pode ser considerado limitado, tendo em vista o potencial do plano diretor municipal, de acordo com as diretrizes definidas na Lei Federal 10257/2001 (BRASIL, 2001). Uma dessas diretrizes, por exemplo, preconiza que o planejamento do Município deve evitar e corrigir as distorções do crescimento urbano e seus efeitos negativos sobre o meio ambiente (BRASIL, 2001). Para que tal diretriz seja efetivada, o plano diretor precisaria ser construído numa perspectiva de maior consideração da UC no seu ordenamento territorial, primeiramente reforçando as restrições de uso e ocupação do solo em seus limites, em consonância com o que está estabelecido na legislação que regulamenta a criação das UCs no Brasil (BRASIL, 2000).

Foram identificadas situações diversificadas quanto à inclusão das UCs nos sistemas de zoneamento municipais investigados, por vezes integrando macroáreas, macrozonas, zonas ou setores destinados à conservação da natureza (planos diretores incluídos na categoria 2). Os planos diretores de Ubatuba e Caraguatatuba, entretanto, apesar de incluírem a UC em uma zona específica no ordenamento territorial do município, não definiram diretrizes para sua proteção, situação semelhante à identificada por Costa et al (2011) numa avaliação de vários planos diretores elaborados no Brasil. Em apenas cinco dos planos diretores investigados (Mongaguá, Peruíbe, Praia Grande, São Sebastião e São Vicente) foram identificadas diretrizes específicas, voltadas para a proteção das UCs.

Dentre os planos diretores analisados, quatro delimitaram zona específica ao redor das UCs, conforme sugerido por Vitalli et al (2009), com o objetivo de protegê-las (Caraguatatuba, Mongaguá, Peruíbe, Praia Grande), ou indicaram que a lei de uso do solo municipal deveria delimitar posteriormente essa zona de proteção (São Sebastião). No caso de São Vicente, a lei de uso do solo 
Tabela 3 - Abordagem das UCs nos planos diretores analisados

\begin{tabular}{lcccc}
\hline & \multicolumn{4}{c}{ Categorias de abordagem das UCs } \\
\cline { 2 - 4 } Plano diretor & 0 & 1 & 2 & 3 \\
\hline Ubatuba & & & $\times$ & \\
Caraguatatuba & & & $\times$ & \\
São Sebastião & & $\times$ & & \\
Bertioga & & & & \\
Santos & $\times$ & & $\times$ & \\
Cubatão & $\times$ & & $\times$ & \\
São Vicente & & & \\
Praia Grande & & & \\
Mongaguá & & & \\
Itanhaém & $\times$ & & \\
Peruíbe & & & \\
Juquitiba & $\times$ & & \\
Sete Barras & & $\times$ & \\
Tapiraí & $\times$ & & \\
\hline
\end{tabular}

Categoria 0; Não menciona a UC. Categoria 1: Apenas cita a UC como área a ser preservada. Categoria 2: Especifica a UC no zoneamento municipal e/ou define diretrizes para sua proteção. Categoria 3: Explicita articulação entre plano diretor e plano de manejo da UC

municipal estabeleceu uma área de proteção ao redor das UCs, mas o plano diretor não estabeleceu diretamente essa diretriz. O turismo e atividades agropecuárias e urbanas de baixo impacto foram as principais opções elencadas para o uso do solo nas áreas estabelecidas no entorno dos parques estudados.

Dois dos planos diretores analisados explicitaram uma articulação com os planos de manejo da UCs presente nos respectivos municípios - Praia Grande e Peruíbe. Esses planos diretores foram, portanto, os que se mostraram mais inclusivos no tocante às UCs estudadas, apresentando todos os aspectos identificados nesse estudo como indicativos de um compromisso com a proteção das UCs presentes em seus territórios, os quais podem ser assim resumidos:

Inserção da UC em uma zona ou macrozona que teria como objetivo central a conservação ambiental.

Delimitação de uma área de proteção no entorno da UC ou indicação para que ela ocorra, por ocasião da elaboração da lei de uso e ocupação do solo.

Formulação de diretrizes específicas, voltadas para a proteção da UC.

Articulação com os planos de manejo da UC, incorporando, na medida do possível, suas demandas relativas à proteção da UC.

Não foi observada diferença entre os planos diretores em relação a qual UC está em consideração. Cabe ressaltar, entretanto, que enquanto foram analisados doze planos diretores de municípios abrangidos pelo PESM, foram analisados dois planos diretores abrangidos pelo PEXJ e um apenas, nos caso dos parques PECB e PEI. Os municípios de Praia Grande e São Vicente são abrangidos tanto pelo PESM quanto pelo PEXJ. O plano diretor de Praia Grande igualmente abordou o PESM e o PEXJ em seu ordenamento territorial. No caso de São Vicente, o plano diretor definiu diretriz específica apenas para a proteção do PEXJ. O plano diretor de Sete Barras abordou igualmente e, de modo superficial, tanto o PECB, quanto o PEI.

De modo similar, também não foi possível estabelecer uma relação entre os planos diretores considerados mais inclusivos para com as UCs e as características do município relativas a desenvolvimento econômico, porcentagem territorial abrangida pela UC ou tamanho populacional. Outras características, como por exemplo, níveis de participação e controle social no processo de construção do plano diretor poderiam explicar as diferenças observadas entre os planos diretores analisados (ROLNIK, 2011). Muito embora a identificação dos fatores que concorrem para que um município elabore um plano diretor com maior ou menor grau de proteção às unidades de conservação, não tenha integrado os objetivos dessa pesquisa, algumas observações podem ser efetuadas.

A primeira delas é a existência de articulação entre as prefeituras e o órgão responsável pela administração da UC, por ocasião da elaboração do plano diretor municipal. Essa integração poderia facilitar a adoção pelo plano diretor, das normas e recomendações definidas no plano de manejo das UCs existentes no município, contribuindo para uma maior efetividade das mesmas (NEVES, 2012). Além disso, a existência de um sistema de planejamento territorial integrado (KOLHOFF \& SLOOTWEG, 2005; SÖDERMAN \& SAARELA, 2010), bem como a incorporação da AAE ao processo de planejamento (SÖDERMAN \& SAARELA, 2010) também poderiam favorecer a articulação necessária entre os diversos níveis e setores de governo (FREITAS, 2008) e, também, a coordenação entre os instrumentos de planejamento atuantes no entorno das áreas protegidas (GARCIA \& REVAH, 2013; ESTEVES \& SOUZA, 2014).

A incorporação da AAE ao processo de planejamento também poderia, ainda, permitir uma maior discussão entre os atores envolvidos, durante a elaboração do plano diretor (FABBRO NETO \& SOUZA, 2009). Esse é um momento em que os gestores da UC e, também, seu Conselho Gestor deveriam atuar fortemente no sentido de mostrar à população, a importância da área protegida para o município. O caráter participativo, imbuído na concepção do plano diretor segundo o Estatuto da Cidade (BRASIL, 2001), confere a esse instrumento uma oportunidade para que os atores sociais, sensibilizados com a importância da área protegida, participem ativamente do processo de tomada de decisão sobre a forma mais adequada de ocupação do seu entorno.

\section{Conclusões}

Os resultados apresentados apontam que ainda não há uma homogeneidade em termos de inclusão das UCs nos planos diretores municipais. Em cinco dos catorze planos diretores municipais analisados, a existência da UC no território municipal não é sequer mencionada 
e em dois deles há apenas essa menção, sem nenhuma outra ação prevista para promover a integração entre o município e a UC. Por outro lado, sete dos catorze planos diretores analisados apresentaram algum grau de inclusão das unidades de conservação no ordenamento territorial do município, sendo que apenas dois deles, explicitaram a articulação entre os citados planos e as UCs presentes nos municípios.

Os aspectos que caracterizaram a construção de planos diretores comprometidos com a proteção das UCs existentes no território do município podem ser assim resumidos:

Inserção da UC em uma zona ou macrozona que teria como objetivo central a conservação ambiental.

Delimitação de uma área de proteção no entorno da UC ou indicação para que ela ocorra, por ocasião da elaboração da lei de uso e ocupação do solo.

Formulação de diretrizes específicas, voltadas para a proteção da UC.

Articulação com os planos de manejo da UC, incorporando, na medida do possível, suas demandas relativas à proteção da UC.

Espera-se que as informações geradas pelo presente estudo possam contribuir com o planejamento territorial em nível local, especialmente no tocante a sua relação com o planejamento da conservação da natureza. Nesse sentido, seria importante que os planos diretores municipais fossem elaborados numa perspectiva de integração entre os diversos instrumentos de planejamento existentes (planos de bacia, ZEE, planos de manejo de UCs) e, também, de articulação entre os diversos órgãos envolvidos com o planejamento do território municipal, incluindo os gestores das áreas protegidas. Como continuidade desse estudo seria importante investigar um número maior de planos diretores de municípios com UCs presentes em seus territórios, bem como avaliar seus respectivos processos de elaboração, de modo a permitir a identificação dos fatores determinantes para a construção de planos diretores mais inclusivos com relação à proteção de áreas naturais.

\section{Referências}

ATLAS DO DESENVOLVIMENTO HUMANO NO BRASIL. 2013. Disponível em: http://atlasbrasil.org. br/2013/.

BRASIL. Presidência da República. Casa Civil. Subchefia para Assuntos Jurídicos. Lei 9985, de 18 de junho de 2000. Institui o Sistema Nacional de Unidades de Conservação e dá outras providências. 2000. Disponível em: http:// www.planalto.gov.br/ccivil_03/leis/L9985.htm.

BRASIL. Presidência da República. Casa Civil. Subchefia para Assuntos Jurídicos - (2001) Lei 10257 (Estatuto das Cidades), de 10 de julho de 2001. Regulamenta os art. 182 e 183 da Constituição Federal, estabelece diretrizes gerais da política urbana e dá outras providências. Disponível online em: http://www.planalto.gov.br/ccivil_03/leis/ LEIS_2001/L10257.htm.
BRASIL. Ministério do Meio Ambiente. Resolução CONAMA n 428, de 17 de dezembro de 2010. Revoga as

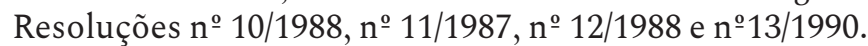
Altera as Resoluções n 347/2004 e nº 378/2006. 2010. http:// www2.mma.gov.br/port/conama/legiabre.cfm?codlegi=641.

BARDIN, L. Análise de conteúdo - Edição Revista e Ampliada. Lisboa: Edições 70, LDA. 2016.

COSTA, H S M, CAMPANTE, A L G, ARAÚJO, R P Z. A dimensão ambiental nos planos diretores de municípios brasileiros: um olhar panorâmico sobre a experiência recente. In: SANTOS JUNIOR, O. A.; MONTANDON, D. T. (Orgs.). Os planos diretores municipais pósEstatuto da Cidade: balanço crítico e perspectivas. Rio de Janeiro: Letra Capital, 2011.p. 173-217. http:// bibspi.planejamento.gov.br/bitstream/handle/iditem/302/ Livro_Os_planos_diretores_municipais_ps_EC_balano_ crtico_e_perspectivas.pdf? sequence=1\&is Allowed $=y$.

DE FRIES, R, KARANTH, K K, PAREETH, S. Interactions between protected areas and their surroundings in humandominated tropical landscapes. Biological Conservation, 2010;143:2870-2880. http://dx.doi.org/10.1016/j. biocon.2010.02.010.

ESTEVES, A O, SOUZA, M S. Avaliação Ambiental Estratégica e as Áreas de Proteção Ambiental. Engenharia Sanitária e Ambiental, 2014;19:77-86. http://dx.doi. org/10.1590/S1413-41522014019010000443

FABRO NETO, F, SOUZA, M P. Avaliação Ambiental Estratégica e desenvolvimento urbano: contribuições para o plano diretor municipal. Minerva, 2009;6(1):85-90. Disponível online: http://www.fipai.org.br/Minerva\%20 06(01)\%2010.pdf.

FIDELIS,T., SUMARES, D. Nature conservation and urban development control in the portuguese planning system: a new impetus against old práxis? European Environment; 2008;18:298-311. DOI:10.1002/eet.487.

FREITAS, I.F. Unidades de Conservação no Brasil: O Plano Estratégico Nacional de Áreas Protegidas e a viabilização da zona de amortecimento [dissertação]. Campinas: FECAU/UNICAMP; 2009.106p.

GARCIA, D. A. D; REVAH, L.O. La Reserva de la Biosfera Alto Golfo de California y Delta del Río Colorado: planeación territorial. Región y Sociedad; 2013;25(58):5785. Disponível online em: http://www.scielo.org.mx/scielo. php? script=sci_arttext\&pid=S1870-39252013000300003.

GOMES, M. O plano de desenvolvimento urbano - após o Estatuto da Cidade. 2006. Disponível online em: www. mpgo.mp.br/portalweb/hp/9/docs/doutrinaparcel_11.pdf.

KOLHOFF, A.; SLOOTWEG, R. Biodiversity in SEA for spatial plans - experinces from the Netherlands. Journal of Environmental Assessment Policy and 
Management, 2005;7(2):267-286. http://dx.doi.org/10.1142/ S146433320500202X.

NEVES, E.M.S.C. Política ambiental, municípios e cooperação intergovernamental no Brasil. Estudos Avançados, 2012;26. http://dx.doi.org/10.1590/S010340142012000100010 .

PETERSON, K. Screening decisions concerning the likely impacts of plan and projects on Natura 2000 sites. Journal of Environmental Assessment Policy and Management, 2010;12(2):185-214. DOI: http://dx.doi. org/10.1142/S1464333210003553.

ROLNIK, R. Democracy on the Edge: Limits and Possibilities in the Implementation of an Urban Reform Agenda in Brazil. Journal of urban and regional research, 2011;35.2:239-255. DOI:10.1111/j.1468-2427.2010.01036.x.

SANTOS, M. R. R. Contribuições do planejamento ambiental para o planejamento territorial de áreas rurais: proposta de uma estrutura base para elaboração e revisão de Planos Diretores municipais [tese]. São Carlos: Escola de Engenharia de São Carlos/USP; 2014.

SANTOS, M .R. R.; RANIERI, V.E.L. Critérios para análise do zoneamento ambiental como instrumento para planejamento e ordenamento territorial. Ambiente \& Sociedade, 2013;16(4):43-62.

SÃO PAULO. Secretaria de Estado do Meio Ambiente. Parque Estadual Serra do Mar - Plano de Manejo. Fundação Florestal. São Paulo. 2006. 433p. Disponível em: http://fflorestal.sp.gov.br/pagina-inicial/planos-demanejo/planos-de-manejo-planos-concluidos/plano-demanejo-pe-serra-do-mar/.

SÃO PAULO. Secretaria de Estado do Meio Ambiente. (2008) Parque Estadual Calos Botelho - Plano de Manejo. Fundação Florestal. São Paulo. 2008. 501 p. Disponível em: http://fflorestal.sp.gov.br/pagina-inicial/planos-demanejo/planos-de-manejo-planos-concluidos/plano-demanejo-pe-carlos-botelho/.

SÃO PAULO. Secretaria de Estado do Meio Ambiente. (2008) Parque Estadual Intervales - Plano de Manejo . Fundação Florestal. São Paulo. 2008. 1100p. Disponível em: http://fflorestal.sp.gov.br/pagina-inicial/planos-demanejo/planos-de-manejo-planos-concluidos/plano-demanejo-pe-intervales/.

SÃO PAULO. Secretaria de Estado do Meio Ambiente. Parque Estadual Xixová-Japuí - Plano de Manejo. Fundação Florestal. São Paulo. 2010. 487p. Disponível em: http://fflorestal.sp.gov.br/pagina-inicial/planos-demanejo/planos-de-manejo-planos-concluidos/plano-demanejo-pe-xixova-japui/.

SÃO PAULO. Secretaria do Meio Ambiente. ZEE Baixada Santista: zoneamento ecológico-econômico - setor costeiro da Baixada Santista. Organização Luiz Roberto Numa de Oliveira. São Paulo: SMA, 2013.104p. Disponível em: http://arquivos.ambiente.sp.gov.br/cpla/2011/05/ZEE_ PUBLICACAO.pdf.

SÃO PAULO. Secretaria do Meio Ambiente. Coordenadoria de Planejamento Ambiental (CPLA). 2014.Disponível online em: http://www.ambiente.sp.gov. $\mathrm{br} / \mathrm{cpla} /$ zoneamento/gerenciamento-costeiro/.

SÃO PAULO. Secretaria do Meio Ambiente. Coordenadoria de Planejamento Ambiental Estratégico e Educação Ambiental. Zoneamento Ecológico-Econômico - Litoral Norte. São Paulo: SMA/CPLEA, 2017. Disponível em: https://www.ambiente.sp.gov.br/cpla/zoneamento/ zoneamento-ecologico-economico/litoral-norte/.

SÖDERMAN, T.; SAARELA, S. Biodiversity in Strategic Environmental Assessment (SEA) of municipal spatial plans in Finland. Impact Assessment and Project Appraisal, 2010;28(2):117-133. Disponível em: http:// doi.org//10.3152/146155110X498834.

SOS Mata Atlântica. 2015. Disponível online em : www. sosma.org.br/projeto/planos-de-mata-atlantica/.

VitAlli, P. L.; ZAKIA, M. J. B. DURIGAN, G. Considerações sobre a legislação correlata à zona tampão de Unidades de Conservação no Brasil. Ambiente e Sociedade, 2009;12(1):87-92. http://dx.doi.org/10.1590/ S1414-753X2009000100006. 